\title{
Material Models to Study the Effect of Fines in Sandy Soils Based on Experimental and Numerical Results
}

\author{
A. Alnmr ${ }^{1, *}$ \\ ${ }^{1}$ Széchenyi István University, Department of Structural and Geotechnical \\ Engineering \\ Egyetem tér 1, 9026 Györ, Hungary \\ *e-mail: ammar888999@hotmail.com
}

Submitted: 18/05/2021; Accepted: 24/11/2021; Published online: 24/11/2021

Abstract: Choosing and calibrating a robust and accurate soil material model (constitutive model) is the first important step in geotechnical numerical modelling. A less accurate model leads to poor results and more difficulty estimating true behaviour in the field. Subsequent design work is compromised and may lead to dangerous and costly mistakes. In this research, laboratory experimental results were used as a basis to evaluate several soil material models offered in Plaxis2D software. The deciding feature of the soil model was how well it could represent effects of percentage of fine material within sandy soils to simulate its behaviour. Results indicate that the Hardening Soil (HS) model works well when the percentage of fine (soft) materials is less than $10 \%$. Above that level, the Soft Soil model (SS) becomes the most suitable. Finally, some important conclusions about this research and recommendations for future research are highlighted.

Keywords: sandy soil, Sand, fine material, consolidation, constitutive model

\section{Introduction}

In numerical calculations, the relationships between stresses and strains in a given substance are represented by a constitutive model, which consists of mathematical expressions that model the behaviour of the soil [1]. The ideal constitutive model 
would faithfully represent soil behaviour in the field, require a small number of parameters gathered from field and laboratory tests, and require minimum computational effort. While no single ideal model exists, a more practical approach is to choose a particular model that performs well under a more limited set of conditions. Such an approach has led to the development of a set of 10-15 material models commonly used in finite element software. Finding the best model for a set of conditions is not always a simple exercise and often requires some trial and error, as well as comparison between different model types.

Finite element analysis has become the de-facto numerical tool to investigate a wide array of geotechnical engineering problems, but the quality of any numerical prediction directly depends on the chosen material model and its required input parameters. The best models would not only predict behaviour previously measured in the field or lab, but also yield reasonable results for a wide variety of design alternatives, loading conditions, and variations in soil lithology and groundwater conditions. These predictions should be useful for considering both serviceability and limit states [2] [1].

While simpler models such as elasto-plastic with Mohr-Coulomb failure condition may be helpful in predicting limit states and estimating movement, many problems require more complex soil behaviour. This becomes especially true when there may be sequences of loading and unloading, construction stages, consolidation, and creep effects that impose very complex loading, drainage, and deformation conditions on a site [2]. Depending on these stages, the soil may compress or expand, its stiffness may vary due to changes in confinement, creep, or shear strain. In fact, the behaviour of the soil is elastic only at a level of very small strains. At slightly higher strain levels, the soil will exhibit a nonlinear stress-strain behaviour.[3] [1].

In contrast to the Mohr-Coulomb (MC) model, the Hardening Soil (HS) and Soft Soil (SS) models [Plaxis Ref] allow for stress dependency of stiffness as well as reduction in stiffness due to shear strain and more sophisticated treatment of dilatancy and yield. The HS and SS models offer a large choice of defining parameters, based on either laboratory testing or back calculated from field experience. The differences between the HS model and the simple MC model can be illustrated by a FE model by Obrzud [5] solving a benchmark excavation problem in Berlin sand from [Schweiger]. Figure 1 shows the displacement fields for an MC model (1a) and HS model (1b). The MC results show an over estimation of elastic rebound and a more general displacement field behind the tie-back wall. The HS results highlight a much lower rebound, more localized movement within the tieback zone and greater vertical settlement at the ground surface directly behind the wall. These estimates were consistent with observations and monitoring results. 


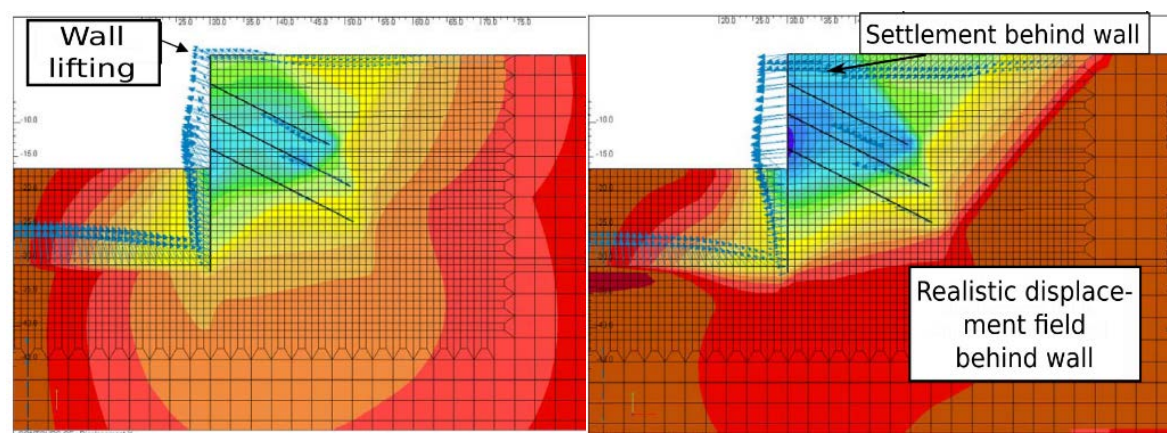

(a)

(b)

Figure 1. Comparison of numerical predictions of horizontal displacements of excavation wall in Berlin sand (a) MC model. (b) HS model [4]

While the qualitative effect percentage of silt content in sand has been known since Terzaghi, quantifying that effect has proved more elusive. Thevanayagam [5] presented a structured approach by considering the silty sand as a balanced matrix consisting of two submatrices: the coarser-grain matrix, and the finer-grain matrix, and analyzing how they coexist within the overall framework of particle-particle contact and transfer of forces through the soil. He and other authors Thev et al [6] , Lade [1], Sibley and Polito [7], viewed the behavior as bridging between sand silt where a fairly narrow transition zone existed between the end states. The location of a threshold fines content would dictate when the transition occurred. These authors also studied various engineering properties such as compressibility, shear strength, cyclic stability and pore pressure generation.

It is worth noting that sand does not exist without other components, but it contains a percentage of fine materials within it, and according to it, the sandy soils has been divided into zones which are zone1, transitional zone and zone2 [8]. Zone 1 is the zone in which fine materials partially fill the voids between the sand grains, meaning that the voids between the sand grains are not completely filled and the sand grains are in contact with each other, while transitional zone which is the zone that gives the lowest values of compressibility. It was found that the percentage of fine material in transitional zone for poor-graded sandy soils ranges between $10-15 \%$, which is the soil used in this research [8]. transitional zone varies according to the grain gradation [8] [9], particle shape and size of sands [10]. In well-graded sand, the percentage of fine material in transitional zone may range between $15-30 \%$ [9]. At transitional zone fine material fills all the voids between sand grains and sand grains 
remain in contact with each other, and thus it plays a major role in the behavior of sandy soils. While zone 2 is the zone where fine materials fill the spaces between the sand grains and separate them from each other, which means that the sand grains are not in contact with each other and the fine materials control the behavior in this region,

Adding various amounts of silt to the host sand causes a noticeable strain-softening response in the behavior even at high relative densities, this difference is represented by the reduced strain-softening behavior and the shift of the steady-state line. However, silty sands present a more tendency to flow contrasted with clean (pure) sand [11] [12]. And as indicated by Porcino et al [13], the addition of fines fundamentally changes the undrained monotonic stress-strain response of sand when tested at a constant void ratio. Up to fines content located at transitional zone, the behavior of the sand-silt blend turns out to be more contractive and strain softening gets more noticeable with increasing fines content, obliging a decrease in the peak and steady-state strengths. Thus, increasing the percentage of fine materials in the sandy soils will affect the choice of the constitutive soil model that simulates its actual behavior. The current study will seek to find out the optimal constitutive soil model according to the percentage of fine materials in sandy soils.

In this paper, both the HS and SS models will be adopted as being advanced models besides that it is easy to get their parameters from the direct shear and consolidation tests. The HS model has proven efficient in simulating soil behavior and has been used in a variety of research [14][15][16][17][18] [19]. The SS model is one of the models capable of simulating the behavior of soft soils with high efficiency. It is a model with better features than the MC model, but it has fewer features than the HS model (Table 1), but it is a specially developed material model for soft soils based on the MCC (Modified Cam Clay) model [20], According to Likitlersuang et al [21], analysis of SS model and HS model with soil parameters determined from laboratory and in situ tests provided better agreement with sidewall movements and field observations of surface settlement.

The magnitude of soil deformations in the HS model can be modelled more precisely by combining three different stiffness parameters taken at a specific reference stress Fig. 2:

1. The triaxial loading stiffness (E50)

2. The triaxial unloading-reloading stiffness (Eur)

3. The oedometer loading modulus (Eoed)

The set of parameters entered into the HS model allows the user to distinguish between loading and unloading - reloading stiffnesses for which a typical ratio is around $\mathrm{E}_{\mathrm{ur}} / \mathrm{E}=3-10$ as the ratio for compression indices $\mathrm{Cc} / \mathrm{Cs}=0.1-0.4$ measured in consolidation tests [4] . 
Table 1. Key features of the MC, SS and HS constitutive models [20]

\begin{tabular}{|c|c|c|c|}
\hline & \multicolumn{3}{|c|}{ Constitutive model } \\
\hline Model feature & $\begin{array}{c}\text { Mohr-Coulomb } \\
\text { Model }\end{array}$ & Soft-Soil Model & $\begin{array}{l}\text { Hardening-Soil } \\
\text { Model }\end{array}$ \\
\hline Non-linear stiffness & $\mathrm{X}^{*}$ & $\mathrm{X}$ & $\mathrm{X}$ \\
\hline $\begin{array}{l}\text { Stress-dependent } \\
\text { stiffness }\end{array}$ & & $\mathrm{X}$ & $\mathrm{X}$ \\
\hline $\begin{array}{l}\text { Different stiffness for } \\
\text { loading/unloading }\end{array}$ & & $\mathrm{X}$ & $\mathrm{X}$ \\
\hline Associated flow & $\mathrm{X}$ & Cap & Cap \\
\hline Non-associated flow & $\mathrm{X}$ & $\mathrm{MC}$ & Cone, MC \\
\hline Stress history effect & & $\mathrm{X}$ & $\mathrm{X}$ \\
\hline Volumetric hardening & & $\mathrm{X}$ & $\mathrm{X}$ \\
\hline Deviatoric hardening & & & $\mathrm{X}$ \\
\hline
\end{tabular}
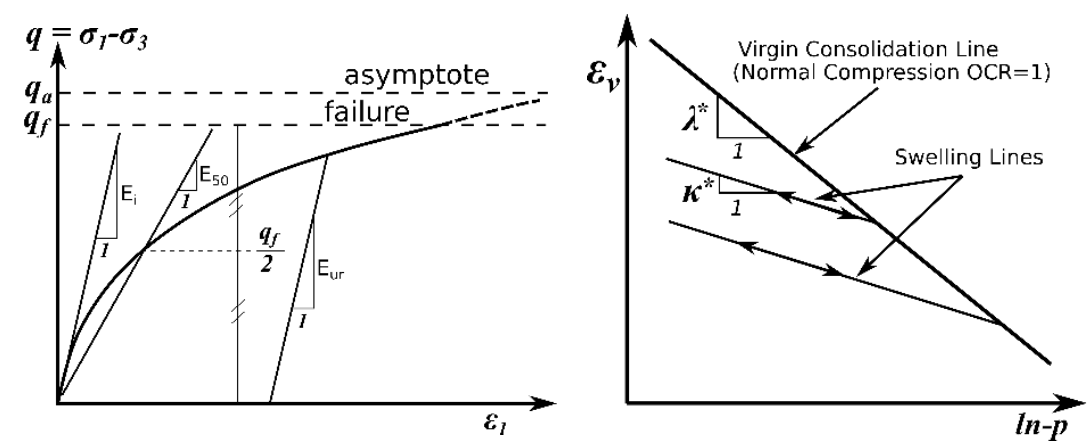

Figure 2. Definitions of moduli for triaxial (left) and oedometer (right) tests [4]

Despite the mathematical complexity of the HS model, its parameters can be determined by conventional soil experiments or can be guessed by following the geotechnical evidence [4]. The HS model represents soil deformations realistically, and for more details about this model go back to [4] [22].

Fig. 2 also shows how to obtain the parameters: $\lambda^{*}$ (modified compression index that determines the compressibility of soil in loading) and $\mathrm{K}^{*}$ (modified swelling index that determines the compressibility of soil in unloading-reloading).

The importance of this research lies in facilitating the task for the researcher to propose the most appropriate model for sandy soil according to the percentage of fine materials within it in order to reach more accurate and reliable results. Whereas, 
engineers looking for realistic predictions of soil response should be aware that by applying the elastic linear model in finite element analysis and not being bound by the limits and constraints of the model used, the soil movements may be mistaken in the guesswork, which in turn affects the amount of forces calculated to support the structural elements.

The research mainly aims to conduct an experimental numerical study of sandy soils mixed with different percentages of fine materials (Silt) in order to determine the optimum constitutive model that simulates the behavior of sandy soils.

\section{Research materials and methods}

In this research, the analytical experimental methodology was followed, whereby homogeneous samples of sandy soil consisted of different percentages of fine materials mixed with poorly-graded sand, were formed in order to conduct laboratory consolidation experiments on them. Finally, consolidation experiments were modelled using Plaxis2D software, using two constitutive models SS and HS.

The fine marine sand was brought from Sanawbar Jableh site in Lattakia, it was wet sieving on the N200 sieve to ensure that it is free from fine materials and obtaining completely pure sand.

While the silty soil was brought from the youth housing site in Latakia. The fine material used in this research was separated from the course material by wet sieving on the N200 sieve. Wet sieving was used because the silty soils agglomerate in their dry state therefore separating fine material with dry sieving will be difficult and will cause a lot of dust.

\subsection{The laboratory work}

Mixtures of sand- fine material were prepared based on dry weight. The fine marine sand was mixed with different percentages of fine materials 5, 10, 15, 20, 25, 30, 35, 45\%. Laboratory experiments were performed on mixtures in the laboratories of the Faculty of Civil Engineering at Tishreen University in Lattakia, as follows:

1. Grain size distribution experiments were carried out according to ASTM D6913 [24] for sand and ASTM D7928-17 [25] for fine material, the granular gradient curves are shown in Fig. 3. We note from Fig. 3 that fine material consists of $38 \%$ of clay and $62 \%$ of silt. Table 2 shows the values of the coefficient of uniformity $(\mathrm{Cu})$ and the coefficient of curvature $\left(\mathrm{C}_{\mathrm{z}}\right)$ of the mixtures. 
A. Alnmr - Acta Technica Jaurinensis, Vol. 14, No. 4, pp. 651-680, 2021

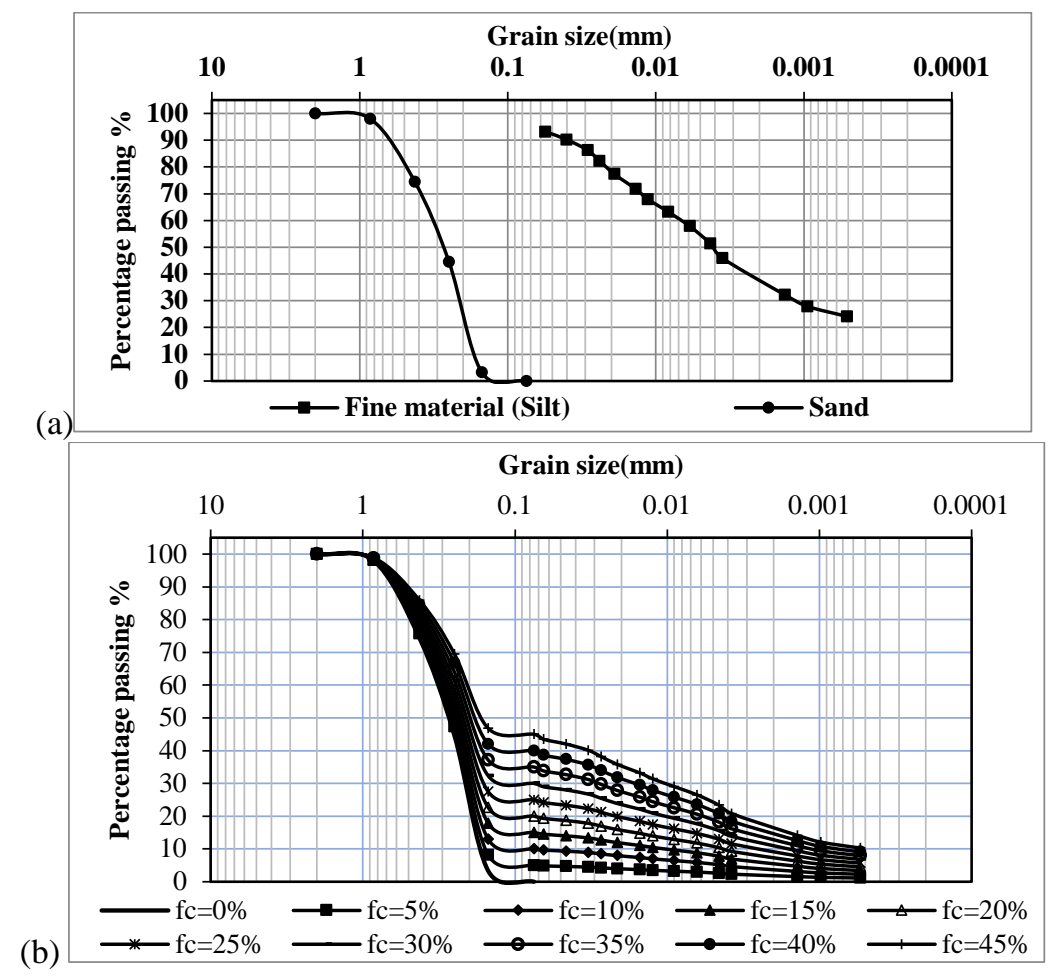

Figure 3. Grain Size Distribution experiments (a)- for sand and silt (b)for mixtures

2. Specific gravity weight (G) tests were conducted according to ASTM D854-14 [26], and the results are presented in Table 2. 
Table 2. Coefficient of uniformity $\left(C_{u}\right)$, coefficient of curvature $\left(C_{z}\right)$ and Specific gravity weight $(G)$ for mixtures

\begin{tabular}{|c|c|c|c|}
\hline $\begin{array}{c}\text { Percentage of added } \\
\text { fine materials }[\%]\end{array}$ & $\begin{array}{c}\text { Specific gravity } \\
\text { weight }(\boldsymbol{G})\end{array}$ & $\begin{array}{c}\text { coefficient of } \\
\text { uniformity }\left(\boldsymbol{C}_{\boldsymbol{u}}\right)\end{array}$ & $\begin{array}{c}\text { coefficient of } \\
\text { curvature }\left(\boldsymbol{C}_{\boldsymbol{z}}\right)\end{array}$ \\
\hline $\mathbf{0}$ & 2.650 & 1.72 & 0.79 \\
\hline $\mathbf{5}$ & 2.652 & 1.88 & 0.83 \\
\hline $\mathbf{1 0}$ & 2.654 & 4.00 & 1.60 \\
\hline $\mathbf{1 5}$ & 2.656 & 18.71 & 7.21 \\
\hline $\mathbf{2 0}$ & 2.658 & 59.83 & 24.73 \\
\hline $\mathbf{2 5}$ & 2.659 & 74.29 & 35.60 \\
\hline $\mathbf{3 0}$ & 2.661 & 119.05 & 10.71 \\
\hline $\mathbf{3 5}$ & 2.663 & 167.83 & 9.47 \\
\hline $\mathbf{4 5}$ & 2.666 & 363.64 & 1.27 \\
\hline
\end{tabular}

3. Atterberg limits experiments were conducted for fine material (according to ASTM D4318-17e1 [27]), and it was found that the plasticity index was $26 \%$ and the liquid limit was $57 \%$, so it was classified as $\mathrm{MH}$ (High Plasticity Silt) according to the Unified Soil Classification System [28].

4. Maximum and minimum void ratio - Experiments were conducted according to the specification (ASTM D4254-00) [29], where the dry soil in its loosened state was filled in a mold size of $2825 \mathrm{~cm}^{3}$ three times and then weighed to calculate the maximum void ratio $\left(\mathrm{e}_{\max }\right)$ and the average results were adopted for each percentage of fine material. After the mixture has been prepared into the mold it was placed on the shaking table and the table was left to vibrate for at least 2 minutes until the height of the soil in the mold became stable and unchanged. After that, the new height of soil in the mold was measured and the minimum void ratio $\left(\mathrm{e}_{\min }\right)$ was calculated. Fig. 5 shows the change of the maximum and minimum void ratio with an increase in the percentage of fine materials.

Fig. 4- (b) shows the results of $e_{\max }$ and $e_{\min }$ for different studies which used different types of sands, where the results of the experiment show the existence of three distinct zones [8] [9]. At the transition zone, the fine materials fill the entire voids between the grains of sand and thus the void ratios are at the lowest values and thus lowest compressibility [8] [9]. This transition zone depends on grain size distribution, packing density, size and shape of the sand and it falls within the range of $10-30 \%$ of added fine materials as shown in Fig 5- (b), as a result, the fine materials have an important role in controlling sandy soil behavior. 


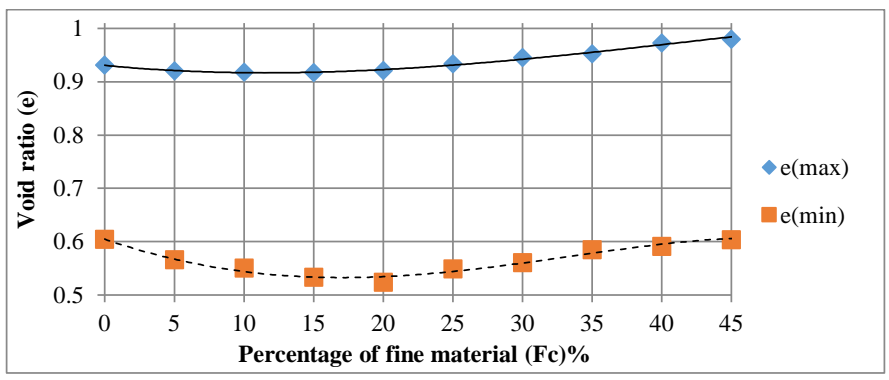

(a)

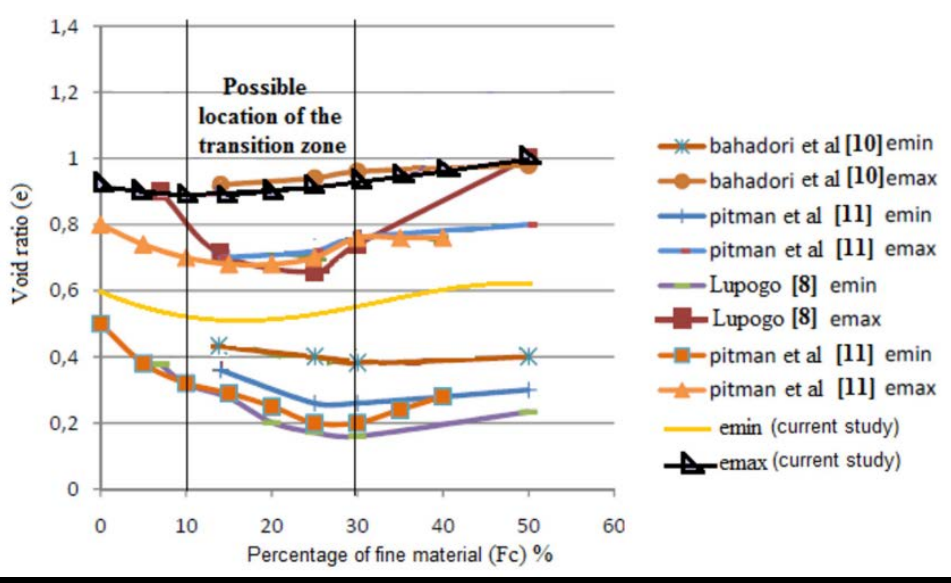

Figure 4. Curves of the relationship between the void ratio and the percentage of fine materials used in this study,(a)-current study (b-) comparison with other studies (adapted from Lupogo [30] )

5. The oedometer tests were conducted according to ASTM D2435 / D2435M 11 [31], where, at first, mixtures of sand - silt were prepared on the basis of dry weight, and for each percentage of silt the required weight of silt and sand were found and mixed manually until it became homogeneous, thereafter the required water percentage was added then it was left for 24 hours in a tightly closed plastic bag in an isolated place to achieve homogeneous moisture in the sample, after the expiration of this period it was mixed manually again for a period of 15 minutes, thus achieving the desired satisfactory homogeneity of the samples as possible. Fig. 5 shows some pictures of laboratory samples with different percentages of silt. The vertical stresses were applied according to the following 
sequence: $0.25,0.50,1,2,4,6,8,6,4,6,8,12 \mathrm{~kg} / \mathrm{cm}^{2}$. Fig. 6 shows the consolidation test device.
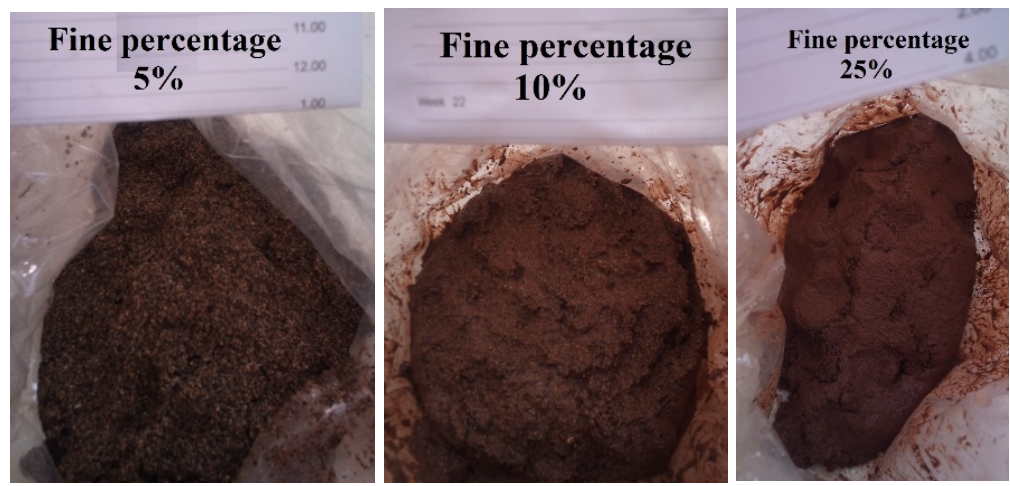

Figure 5. Pictures of some laboratory samples with different percentages of silt

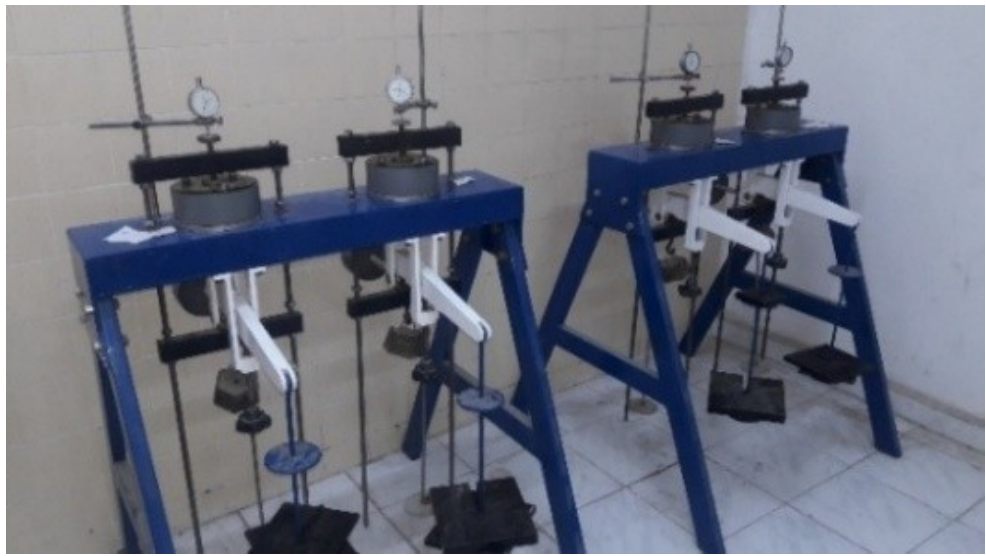

Figure 6. Consolidation test device

6. Direct shear experiments were also conducted for all percentages of silt adopted in this research. Fig.7 shows the direct shear test device. Table 3 shows the physical properties of samples used in the direct shear and consolidation tests. The mixtures were tested with a relative density of $50 \%$ and initial moisture of $24 \%$ close to the saturation moisture. 


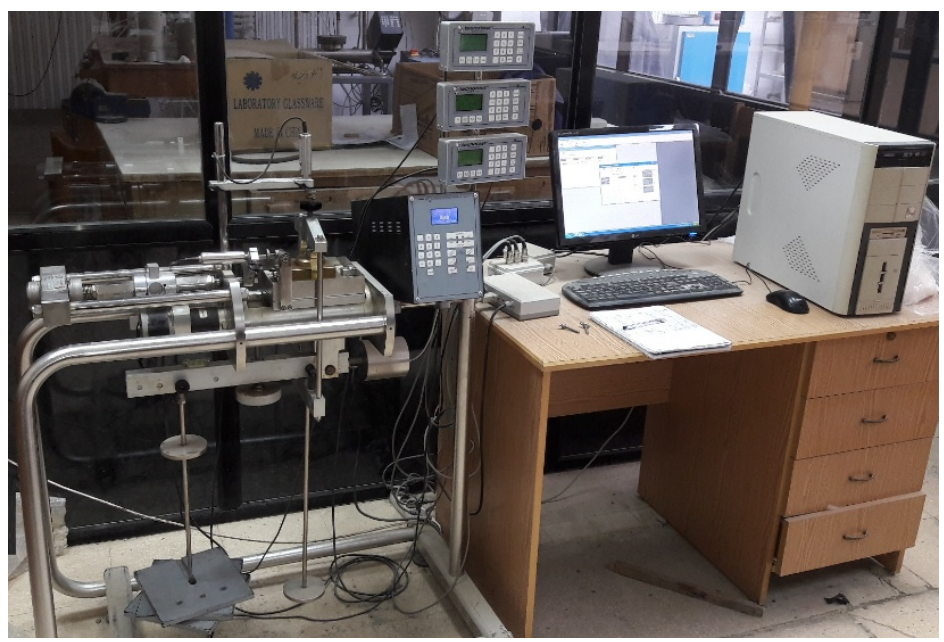

Figure 7. Direct shear device

Table 3 . The samples used in the direct shear and consolidation experiments.

\begin{tabular}{|c|c|c|c|c|c|c|c|}
\hline $\begin{array}{c}\text { Sample } \\
\text { symbol }\end{array}$ & $\begin{array}{c}\text { Percentage of } \\
\text { fine materials } \\
\text { (Fc) } \\
\mathbf{\%}\end{array}$ & $\mathbf{e}_{\max }$ & $\mathbf{e}_{\mathbf{m i n}}$ & $\begin{array}{c}\text { Moisture } \\
{[\%]}\end{array}$ & $\begin{array}{c}\text { Dry } \\
\text { density } \\
{\left[\mathbf{g r} / \mathbf{c m}^{3}\right]}\end{array}$ & $\begin{array}{c}\text { Void } \\
\text { ratio } \\
{[\mathbf{e}]}\end{array}$ & $\begin{array}{c}\text { Relative } \\
\text { density } \\
\mathbf{\%}\end{array}$ \\
\hline S1 & $\mathbf{0}$ & 0.931 & 0.604 & 24 & 1.499 & 0.768 & 50 \\
\hline S2 & $\mathbf{5}$ & 0.920 & 0.566 & 24 & 1.521 & 0.743 & 50 \\
\hline S3 & $\mathbf{1 0}$ & 0.918 & 0.550 & 24 & 1.531 & 0.734 & 50 \\
\hline S4 & $\mathbf{1 5}$ & 0.917 & 0.533 & 24 & 1.540 & 0.725 & 50 \\
\hline S5 & $\mathbf{2 0}$ & 0.921 & 0.524 & 24 & 1.543 & 0.722 & 50 \\
\hline S6 & $\mathbf{2 5}$ & 0.933 & 0.549 & 24 & 1.527 & 0.741 & 50 \\
\hline S7 & $\mathbf{3 0}$ & 0.945 & 0.560 & 24 & 1.518 & 0.753 & 50 \\
\hline S8 & $\mathbf{3 5}$ & 0.952 & 0.585 & 24 & 1.506 & 0.769 & 50 \\
\hline S9 & $\mathbf{4 5}$ & 0.979 & 0.604 & 24 & 1.488 & 0.791 & 50 \\
\hline
\end{tabular}

Plaxis 2D finite element software was utilized to simulate the consolidation phenomenon in the oedometer test. An axisymmetric model having dimensions 
similar to the dimensions of a ring of oedometer test used in this study. A very fine mesh was used for greater precision during matrix solving. Total fixities for the bottom bound of the model and horizontal fixities for the side borders of the model are used. The vertical distributed load $(\mathrm{P})$ was applied over the entire length of the top surface to represent the phases of the load during the loading and reloading process. The default value for this load is $1 \mathrm{kPa}$, and it was changed during the deactivation stages of the calculation phases. Fig. 8 shows the model prepared in Plaxis and the mesh of finite elements, the distributed load, the boundary conditions, and geometric dimensions. To simulate the loading steps that were used in the laboratory, the vertical load was determined in the calculation program as different phases. A point was identified on the top surface to track the load-displacement behavior. In order to represent the loading and reloading stage in the calculation program in Plaxis, the calculation phases allow the required (applied) load to change during the load activation before the phase is updated. This means that for the next stage, the applied load can easily be changed (increased or decreased), as the method of modelling the loading stages in this paper is similar to the method that followed by Aldefae [19].

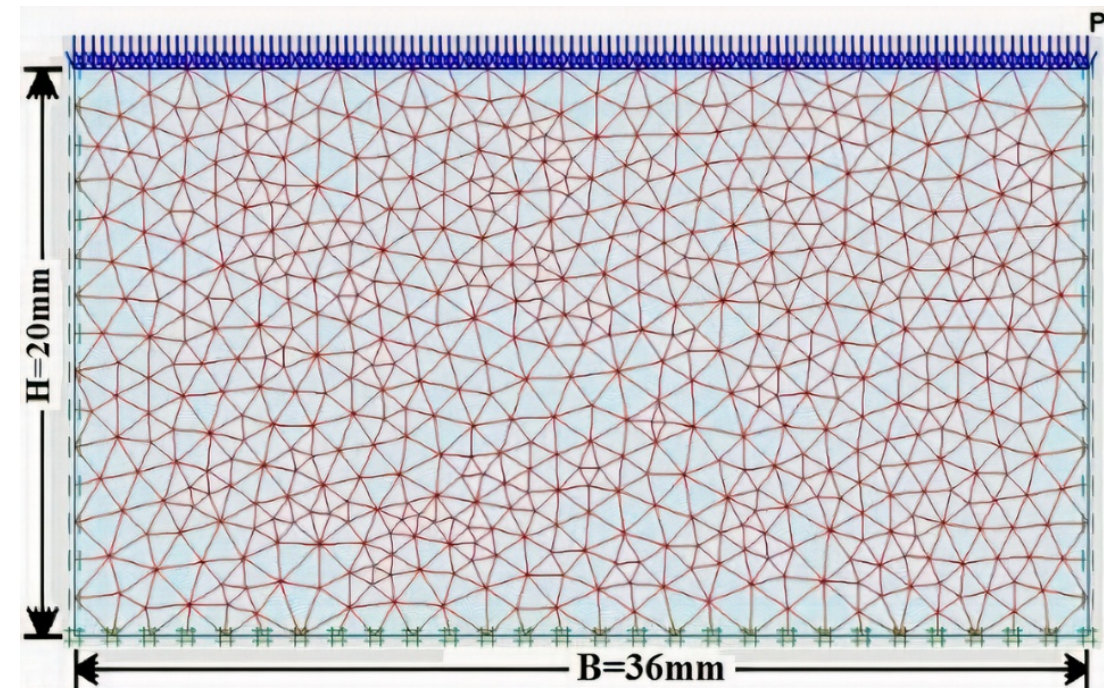

Figure 8. Geometry and finite element mesh for one-dimension consolidation problem

Fig. 9 shows the used phases during calculation processing as it shown the calculation type is Plastic analysis because we consider that the behaviour of soil as drained and the attention is given for final settlement of each loading step only, since the behaviour of sandy soil is drained, as it is known. Every loading step starts after finishing the previous one, exactly as happening in consolidation (oedometer) test. 


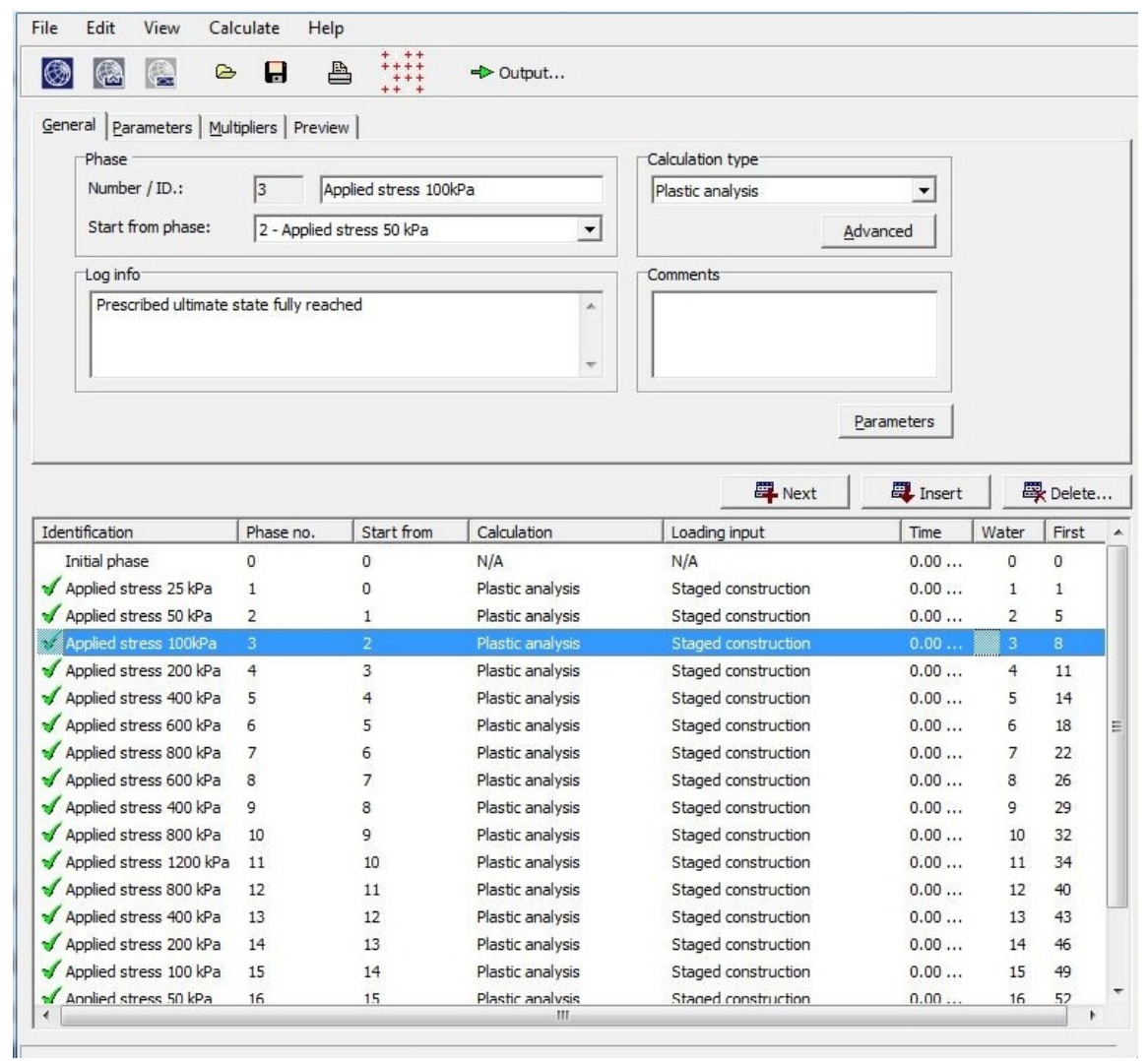

Figure 3. Calculation phases

\section{Results and discussion}

\subsection{Experimental results}

Fig. 10 shows the relationship between the void ratio and the vertical effective stress of the tested samples according to the percentages of added fine materials. It appears from the figure that the inclination of the compression line increases with the increase in the content of added fine material. 


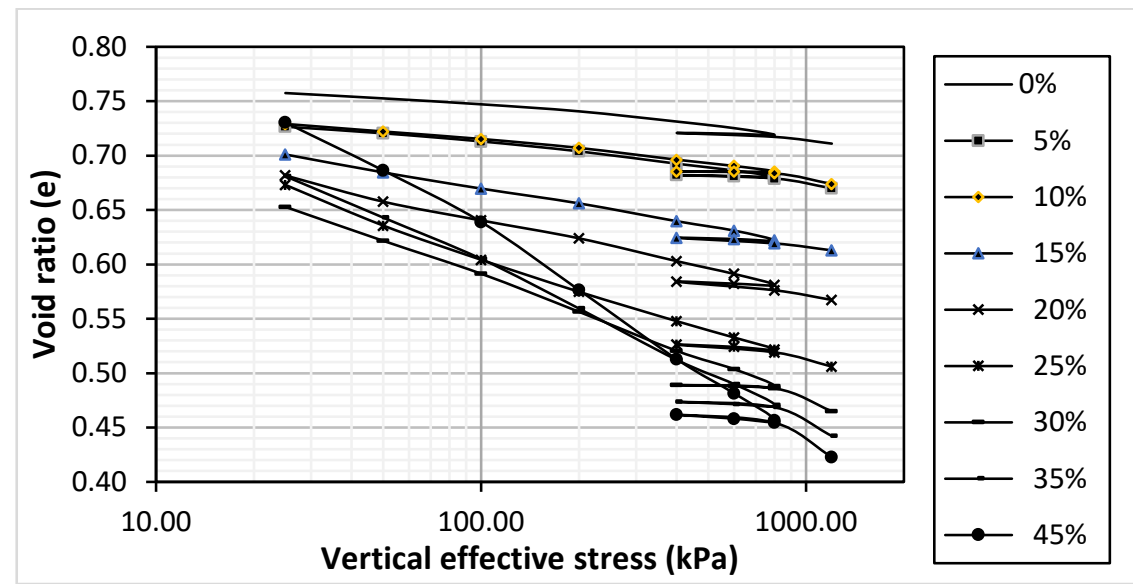

Figure 10. Curves of the relationship between the void ratio and the vertical effective stress of the tested samples according to the percentages of added fine materials

The values of the compression index (Cc) in this study for different effective stresses ranged between 0.018-0.211. And the values of the measured sand-silt compression index are in good agreement with the results of Mesri and Vardhanabhuti [32] \& Monkul and Ozden [33].

the compression index (Cc) is the slope of the linear portion of the curve after pre-consolidation stress, it is calculated using the equation (1).

$$
C_{c}=\frac{e_{0}-e_{1}}{\log \left(\frac{\sigma_{1}^{\prime}}{\sigma_{0}^{\prime}}\right)}
$$

Fig. 11 shows compression index values at each monotonic loading increment for every specimen. The horizontal axis represents the average vertical stress between load increments. There is a definite transition in Cc between low and high fine percentages. The $(0,5,10 \%)$ specimens show identical behaviour until the highest stress level. This may be due to fine fractions carrying some of the internal stress at this level. The fines are more compressible compared to $0 \%$ where grain interlocking may be stabilizing. The next three specimens (15, 20, 25\%) show progressive softening with fine content. The softening reduces at higher stress perhaps due to the sand matrix being more dominant in certain zones. Finally, the last three (30, 35, 45\%) show nearly identical behaviour with overall softening increasing directly proportional to fines content. Therefore, there is a definite "sand zone" and a definite "fines zone" with a less well-defined "transition zone". This evolution of behaviour with fines content has been observed by previous researchers [30] [33] [34]. 


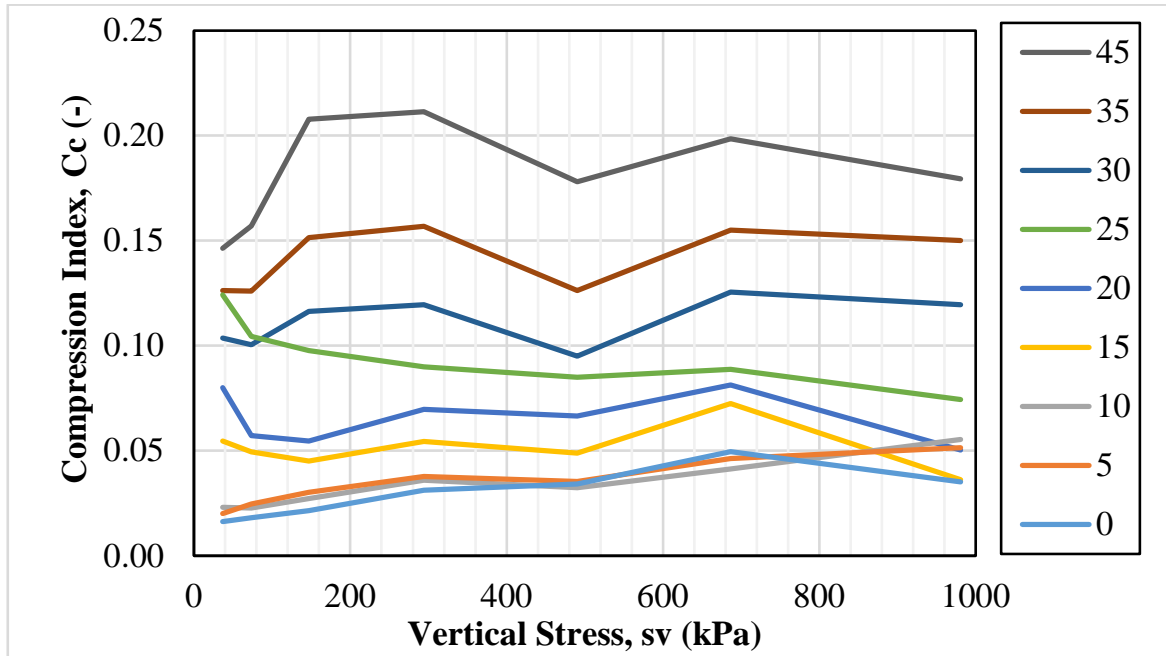

Figure 11. The relationship between the compression index and vertical stress for specimens with increasing percentage of fine materials.

Monkul and Ozden [33] presented an important concept about the transitional percentage of added fine material after which the separation between sand grains occurs. According to this concept, they assumed that the separation of coarse grains may occur when the intergranular void ratio $\left(\boldsymbol{e}_{\boldsymbol{s}}\right)$ of the mixture exceeds the maximum void ratio of the remaining sand matrix.

The intergranular void ratio concept initially assumes only the sand matrix is carrying load. That assumption means for load carrying purposes, the fines matrix is first considered as voids since they do not contribute to carrying load. As percentage of fines increases, this assumption is no longer valid and the impact of fines on the compressibility of sand silt mixture can be quantified. The intergranular void ratio can be written as shown in the equation (2) [33].

$$
e_{s}=\frac{e+\frac{G * f_{c}}{G_{f} * 100}}{\frac{G}{G_{s}} *\left(1-\frac{f_{c}}{100}\right)}
$$

Where: $G_{s}$ and $G_{f}$ are the specific gravity of sand and fine material, respectively. $G$ is the specific gravity of the soil mixture itself.

It is shown from Fig. 12 that the line of the maximum void ratio of sand $\left(\mathrm{e}_{\max }=0.931\right)$ intersects the curves of the relationship between es and percentage of added fine material according to different levels of stresses at the percentage of fine material between 11 to $17 \%$, and this indicates that the contact between the coarse 
grains under the applied stresses occurs when the content of fine materials is between 11 to $17 \%$ and this proves that the percentage of fine materials that achieve the lowest compressibility increases with increasing the applied stress.

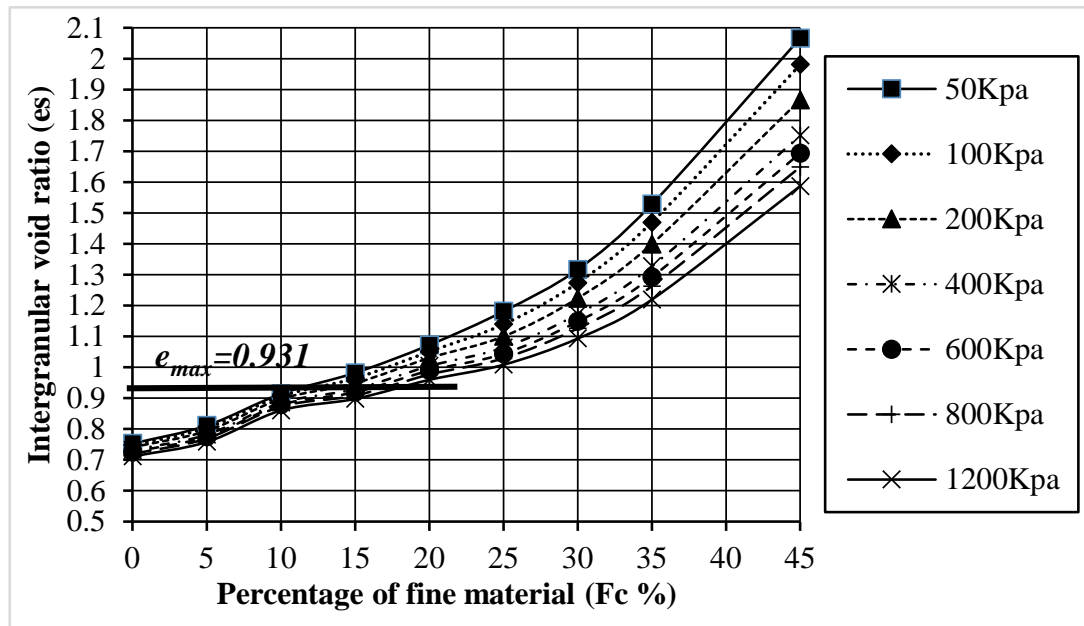

Figure 12. Relationship between intergranular void ratio and percentage of fine material

\subsection{Numerical study}

\subsubsection{Method of fitting}

The best fitting of the curve of the numerical modeling of consolidation test using SS model with the curve of laboratory consolidation test was achieved as follows:

1- The parameter $\boldsymbol{\lambda}^{*}$ was calculated for each percentage of added fine materials at three different ranges of stress, (50-100), (100-200) and (200-400)kPa to take uncertainty into consideration, while the parameter $\mathbf{K}^{*}$ was calculated from the reloading curve of an unloading-reloading cycle for example, for the percentage of added fine materials $35 \%$, the values of $\boldsymbol{\lambda}^{*}$ and $\mathbf{K}^{*}$ are shown in Table 4.

Table 4. Parameters of $\lambda^{*}$ and $K^{*}$ for percentage of added fine materials $35 \%$.

\begin{tabular}{|c|c|c|}
\hline Range of stress (kPa) & $\mathbf{K}^{*}$ & $\boldsymbol{\lambda}^{*}$ \\
\hline $50-100$ & 0.003 & 0.0273 \\
\hline $100-200$ & 0.003 & 0.034 \\
\hline $200-400$ & 0.003 & 0.038 \\
\hline
\end{tabular}


2- For each range of stress, the curve of numerical modeling using SS model was created as shown in Fig. 13.

Finally, the parameters $\lambda^{*}$ and $\mathbf{K}^{*}$ calculated from the considered range of stress, which achieved the best fitting of the curve of the laboratory test, were adopted. As it is seen from Fig. 13 the range of stress (50-100 kPa) achieves the best simulation of the curve of the laboratory test which is also proved in Table 5 (the last row), which shows the sum of the squared error of the three ranges of stress, and we note that this sum is the smallest for the range (50-100), so its parameters are adopted for the percentage of added fine materials $35 \%$. The same methodology was applied to other percentages of added fine materials.

Table 5. The squared error of the three ranges of stress

\begin{tabular}{|c|c|c|c|c|c|c|c|}
\hline б(kPa) & $\mathbf{T}_{35}$ & $\mathbf{P S}_{35,1}$ & $\mathbf{P S}_{35,2}$ & $\mathbf{P S}_{35,3}$ & $\begin{array}{c}\mathbf{( P S}_{35,1^{-}} \\
\left.\mathrm{T}_{35}\right)^{2}\end{array}$ & $\begin{array}{c}\text { (PS }_{35,2^{-}} \\
\left.\mathrm{T}_{35}\right)^{2}\end{array}$ & $\begin{array}{c}\mathbf{P S}_{35,3^{-}} \\
\left.\mathbf{T}_{35}\right)^{2} \\
\end{array}$ \\
\hline 0 & 0 & 0 & 0 & 0 & 0 & 0 & 0 \\
\hline 25 & 0.050 & 0.034 & 0.029 & 0.033 & $2.3 \mathrm{E}-04$ & $4.1 \mathrm{E}-04$ & $2.8 \mathrm{E}-04$ \\
\hline 50 & 0.071 & 0.078 & 0.071 & 0.082 & $4.2 \mathrm{E}-05$ & $9.6 \mathrm{E}-08$ & $1.1 \mathrm{E}-04$ \\
\hline 100 & 0.092 & 0.103 & 0.101 & 0.115 & $1.1 \mathrm{E}-04$ & $6.9 \mathrm{E}-05$ & 5.2E-04 \\
\hline 200 & 0.118 & 0.126 & 0.127 & 0.145 & $5.3 \mathrm{E}-05$ & $8.4 \mathrm{E}-05$ & 7.4E-04 \\
\hline 400 & 0.145 & 0.147 & 0.154 & 0.175 & $4.2 \mathrm{E}-06$ & 7.4E-05 & 8.9E-04 \\
\hline 600 & 0.158 & 0.160 & 0.169 & 0.192 & $3.9 \mathrm{E}-06$ & 1.3E-04 & $1.2 \mathrm{E}-03$ \\
\hline 800 & 0.168 & 0.169 & 0.180 & 0.204 & $6.3 \mathrm{E}-10$ & $1.3 \mathrm{E}-04$ & $1.3 \mathrm{E}-03$ \\
\hline 600 & 0.168 & 0.168 & 0.179 & 0.203 & $2.3 \mathrm{E}-07$ & $1.2 \mathrm{E}-04$ & $1.2 \mathrm{E}-03$ \\
\hline 400 & 0.167 & 0.167 & 0.178 & 0.202 & $9.0 \mathrm{E}-08$ & $1.2 \mathrm{E}-04$ & 1.3E-03 \\
\hline 800 & 0.170 & 0.169 & 0.180 & 0.204 & $3.0 \mathrm{E}-07$ & $1.1 \mathrm{E}-04$ & $1.2 \mathrm{E}-03$ \\
\hline 1200 & 0.185 & 0.182 & 0.195 & 0.222 & $9.0 \mathrm{E}-06$ & $1.1 \mathrm{E}-04$ & $1.4 \mathrm{E}-03$ \\
\hline 800 & 0.184 & 0.180 & 0.194 & 0.220 & $1.3 \mathrm{E}-05$ & $1.0 \mathrm{E}-04$ & $1.3 \mathrm{E}-03$ \\
\hline 400 & 0.182 & 0.178 & 0.192 & 0.218 & $1.2 \mathrm{E}-05$ & $1.1 \mathrm{E}-04$ & $1.4 \mathrm{E}-03$ \\
\hline 200 & 0.179 & 0.177 & 0.191 & 0.217 & $3.9 \mathrm{E}-06$ & $1.4 \mathrm{E}-04$ & $1.5 \mathrm{E}-03$ \\
\hline 100 & 0.176 & 0.175 & 0.189 & 0.215 & $5.6 \mathrm{E}-07$ & $1.8 \mathrm{E}-04$ & $1.6 \mathrm{E}-03$ \\
\hline 50 & 0.172 & 0.174 & 0.187 & 0.214 & $1.1 \mathrm{E}-06$ & $2.3 \mathrm{E}-04$ & $1.7 \mathrm{E}-03$ \\
\hline 25 & 0.168 & 0.173 & 0.186 & 0.213 & $1.6 \mathrm{E}-05$ & 3.3E-04 & $2.0 \mathrm{E}-03$ \\
\hline & & & & $\Sigma$ & 0.0005 & 0.0024 & 0.0195 \\
\hline
\end{tabular}

Where:

$\mathbf{T}_{35}$ is refer to the results of Laboratory test of $35 \%$ of added fine material.

PS $_{35,1}$ refers to the results of the numerical analysis by Plaxis using Soft Soil model of $35 \%$ of added fine material for the range of stress (50-100) $\mathrm{kPa}$.

PS $_{35,2}$ refers to the results of the numerical analysis by Plaxis using Soft Soil model of $35 \%$ of added fine material for the range of stress $(100-200) \mathrm{kPa}$.

$\mathbf{P S}_{35,3}$ refers to the results of the numerical analysis by Plaxis using Soft Soil model of $35 \%$ of added fine material for the range of stress $(200-400) \mathrm{kPa}$ 


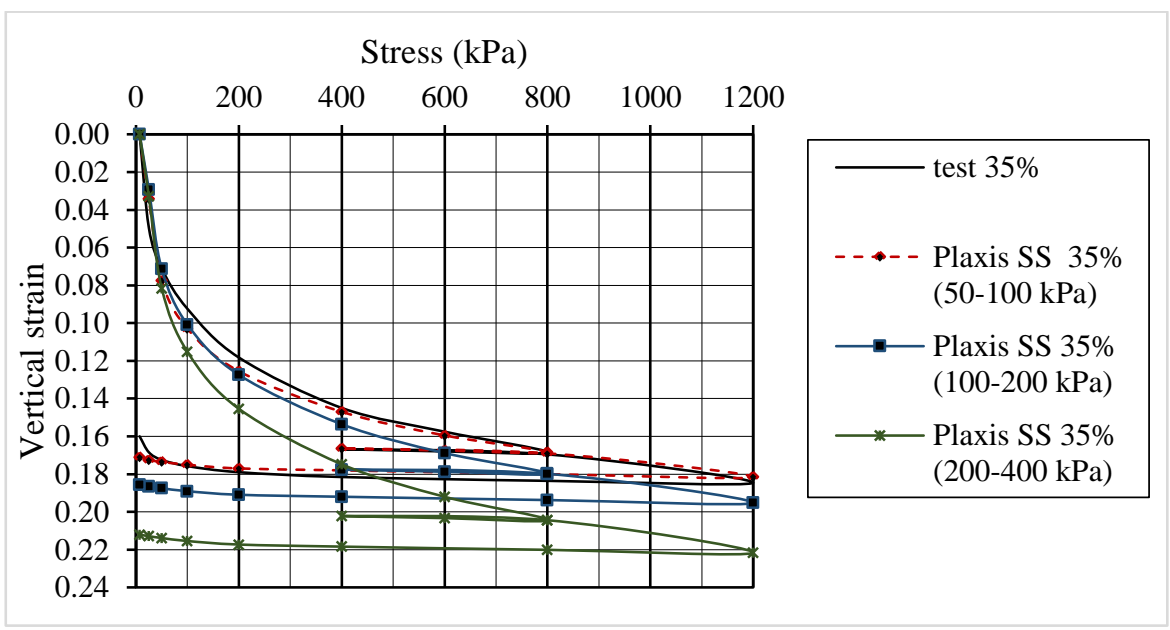

Figure 13. The curves of the stress-strain relationship for both laboratory one-dimension consolidation test and numerical modeling using SS model to determine the best value of $\lambda^{*}$ for the percentage of added fine material $35 \%$

While, achieving the best fitting between the curves of stress- strain relationship for both laboratory one-dimension consolidation test and numerical modeling using HS model required more time and effort and it was done as follows:

1- The most appropriate reference stress $\left(\mathrm{P}_{\mathrm{ref}}\right)$ that achieved the best fitting was determined. The corresponding stiffness parameters were calculated from curve of the relationship between stress and strain of consolidation test for each reference stress 50, 100, 200, $400 \mathrm{kPa}$ where $E_{\text {oed }}^{\text {ref }}$ calculated depending on loading curve, while the parameter $E_{\text {oed }}^{r e f}$ was calculated from the unloading curve for each reference stress, without changing the parameter $m$ in this step, for example, the stiffness parameters corresponding to each reference stress 50-100-200-400 kPa for the percentage of added fine material 35\%, shown in Table 6.

Fig. 14 displays the curves of the stress-strain relationship for both laboratory onedimension consolidation test and numerical modeling using HS model for various reference stresses $\mathrm{P}_{\text {ref }}$ for the percentage of added fine material $35 \%$. 
Table 6. Stiffness parameters of HS model for percentage of added fine materials 35\% for various reference stresses Pref.

\begin{tabular}{|c|c|c|c|}
\hline Pref $_{\text {ref }}$ & $\mathbf{m}$ & $\begin{array}{l}E_{u r}^{r e f} \\
\text { [kPa] }\end{array}$ & $\begin{array}{c}E_{50}{ }^{r e f}=E_{\text {oed }}{ }^{r e f} \\
{[\mathbf{k P a}]}\end{array}$ \\
\hline 50 & 0.7 & 10300 & 1750 \\
\hline 100 & 0.7 & 23000 & 3200 \\
\hline 200 & 0.7 & 52000 & 5700 \\
\hline 400 & 0.7 & 98500 & 10200 \\
\hline
\end{tabular}

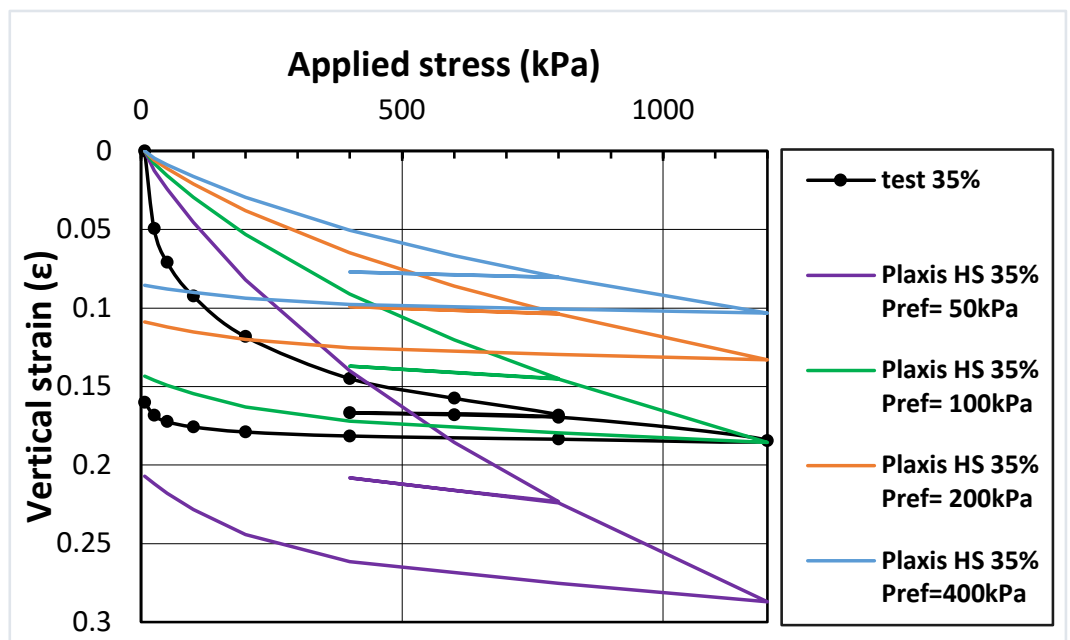

Figure 14. The curves of the stress-strain relationship for both laboratory one-dimension consolidation test and numerical modeling using HS model at various reference stresses Pref for the percentage of added fine material $35 \%$

2- The second step was determining the parameter $\mathrm{m}$. It is noted from the Fig. 14 that the reference stresses $P_{\text {ref }}$ that achieve the best fit are $P_{\text {ref }}=100 \mathrm{kPa}$, so the reference stress $\mathrm{P}_{\text {ref }}$ will be fixed and change the value of $\mathrm{m}$ within the range from 0.5 to 0.9 and adopt the value of the parameter $\mathrm{m}$ that achieves the best fit for the laboratory one-dimension consolidation test.

Fig. 15 shows the numerical modeling curves of the HS model at different values of the parameter $\mathrm{m}$ for the percentage of added fine material $35 \%$. 


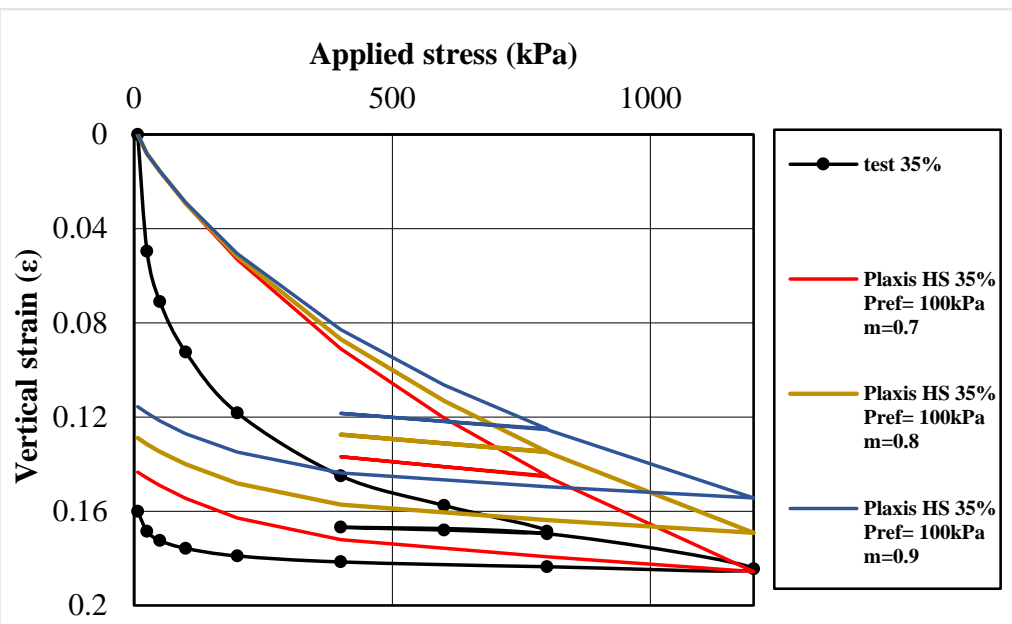

Figure 15. The curves of the stress-strain relationship for both laboratory one-dimension consolidation test and numerical modeling using HS model at various values of the parameter $m$ for the percentage of added fine material $35 \%$

It is obvious from Fig. 15 that HS model does not simulate the laboratory onedimension consolidation test for $35 \%$ of added fine material. The same methodology was applied to all percentages of added fine materials to determine the best parameters for HS model.

\subsubsection{Numerical results}

The above methodology was followed to determine the best parameters for both models HS and SS, based on conducted laboratory experiments. Table 7 shows the best parameters of both the HS and SS models which achieve the best simulation of the one-dimension consolidation experiments, which were extracted from the laboratory experiments conducted for each percentage of fine material.

The results of both the laboratory tests of the one-dimensional consolidation test and finite element with SS and HS models are plotted in a stress-strain relationship. Fig. 16 shows the vertical displacement at the end phase of the numerical test in both the rainbow shading Fig. 17 (a) and in the shape of the arrows Fig.16 (b). The maximum vertical settlement is at the top of the model while zero settlement is at the base of the model and this is identical to what should be in the consolidation test. 
Table 7. Summary of parameters used for FE model

\begin{tabular}{|c|c|c|c|c|c|c|c|c|c|c|}
\hline \multicolumn{2}{|c|}{ SS (SoftSoil) } & \multicolumn{4}{|c|}{ HS (HardeningSoil) } & \multirow[b]{2}{*}{$\begin{array}{c}\gamma_{\text {sat }} \\
{\left[\mathbf{k N} / \mathbf{m}^{3}\right]}\end{array}$} & \multirow[b]{2}{*}{$\begin{array}{c}\Psi \\
{[0]}\end{array}$} & \multirow[b]{2}{*}{$\begin{array}{c}\phi \\
{\left[{ }^{0}\right]}\end{array}$} & \multirow[b]{2}{*}{$\begin{array}{c}\mathrm{C} \\
{[\mathrm{kPa}]}\end{array}$} & \multirow[b]{2}{*}{$\begin{array}{c}\text { Fc } \\
{[\%]}\end{array}$} \\
\hline $\mathbf{K}^{*}$ & $\lambda^{*}$ & $\mathbf{P}_{\text {ref }}$ & $\mathbf{m}$ & $\begin{array}{l}E_{u r}^{r e f} \\
\text { [kPa] }\end{array}$ & $\begin{array}{r}E_{50}^{\text {ref }}=E_{\text {oed }}^{\text {ref }} \\
{[\mathbf{k P a}]}\end{array}$ & & & & & \\
\hline 0.0023 & 0.0047 & 400 & 0.65 & 246100 & 45800 & 19.33 & 9 & 39 & 5 & 0 \\
\hline 0.00184 & 0.006 & 400 & 0.7 & 271100 & 33200 & 19.48 & 8 & 38 & 15 & 5 \\
\hline 0.00141 & 0.0055 & 400 & 0.82 & 296200 & 34000 & 19.54 & 6 & 36 & 23 & 10 \\
\hline 0.0019 & 0.01 & 200 & 0.6 & 85000 & 12500 & 19.6 & 3 & 33 & 35 & 15 \\
\hline 0.003 & 0.0141 & 100 & 0.6 & 51500 & 6900 & 19.62 & 0 & 25 & 44 & 20 \\
\hline 0.002 & 0.0205 & 100 & 0.67 & 41000 & 4300 & 19.53 & 0 & 24.1 & 47 & 25 \\
\hline 0.003 & 0.0273 & 100 & 0.7 & 23000 & 3200 & 19.4 & 0 & 21 & 52 & 35 \\
\hline 0.0035 & 0.0295 & 100 & 0.9 & 12500 & 2400 & 19.3 & 0 & 17 & 55 & 45 \\
\hline
\end{tabular}

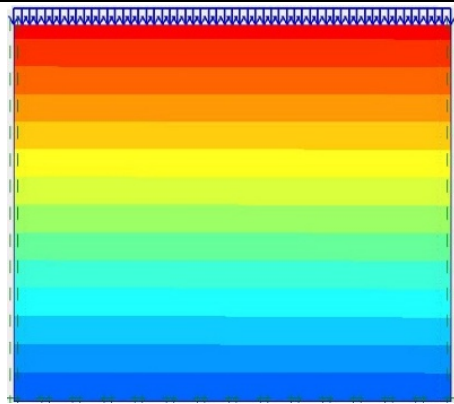

(a)

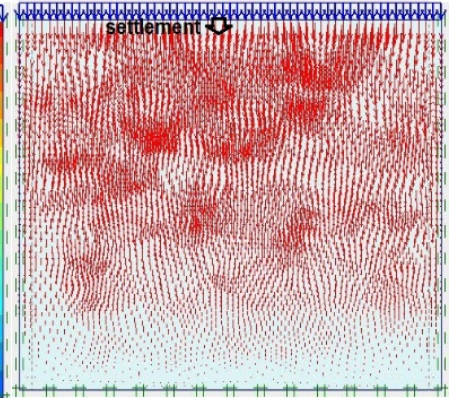

(b)

Figure 16. Vertical displacement of the model (a)- shadings and (b)- arrows.

Fig. 17 shows the curves of the stress-strain relationship for both laboratory onedimension consolidation test and numerical modeling using HS model. There is an almost identical agreement between the two curves when the percentage of added fine material ranges between 0 up to $10 \%$, and after the percentage of $10 \%$ of added fine material the two curves move away from each other. Thus, the HS model gives the best results in sandy soils in which the percentage of fine materials does not exceed $10 \%$, meaning that HS model is suitable for sandy soils located in zone 1 .

Fig. 18 shows the curves of the stress-strain relationship for both laboratory onedimension consolidation test and numerical modeling using SS model as well. But on contrary to the result from Fig. 18, there is a great and almost identical agreement between the two curves when the percentage of added fine material exceeds $10 \%$, whilst if the percentage of added fine material is less than $10 \%$ the two curves move away from each other. Thus, the SS model gives the best results in sandy soils in 
which the percentage of fine materials exceeds $10 \%$, meaning that SS model is suitable for sandy soils located in the Transition zone and zone 2 .
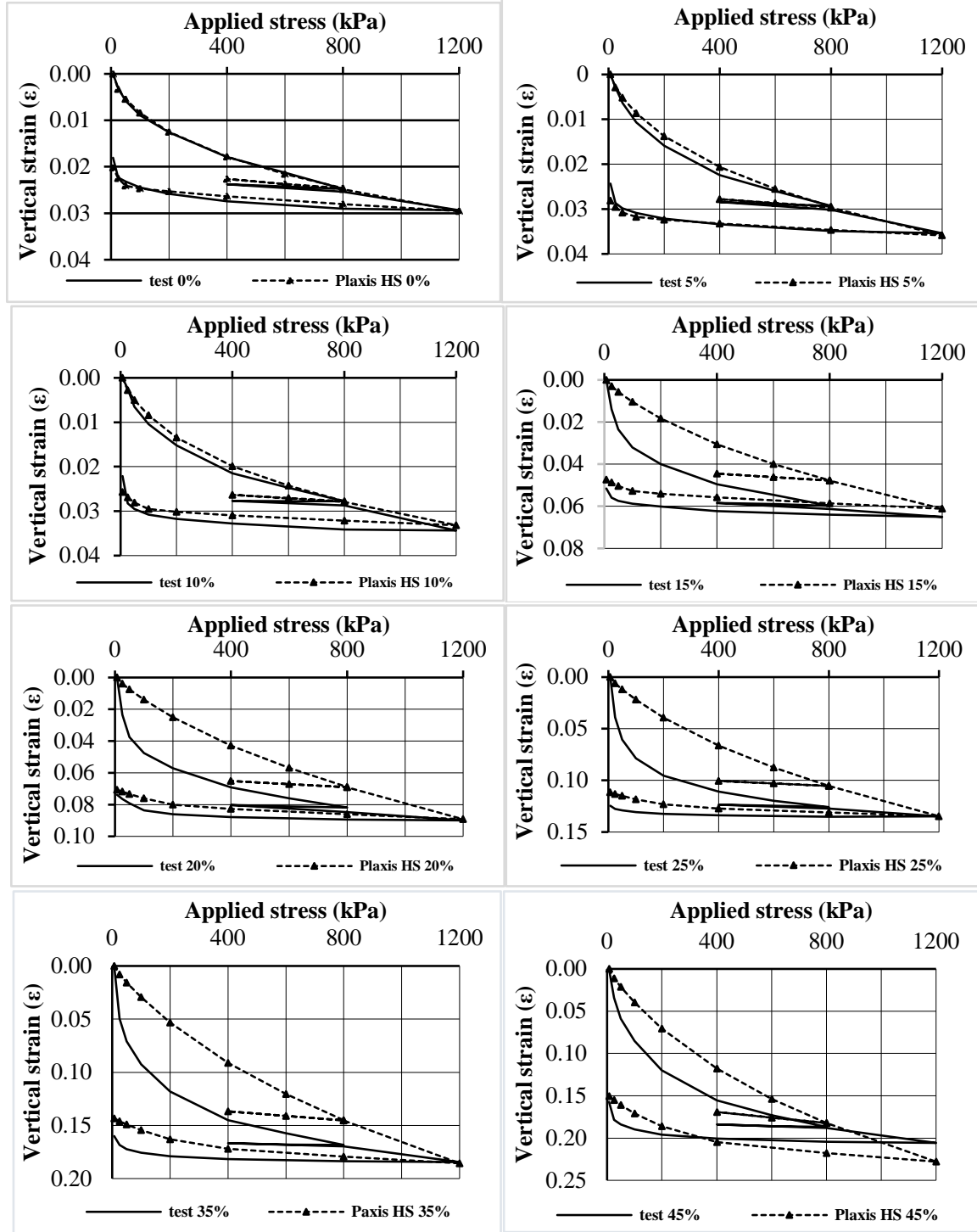

Figure 17. The curves of the stress-strain relationship for both laboratory onedimension consolidation test and numerical modeling using HS model 
Where: test $0 \%$, test $5 \%$ etc mean laboratory one-dimension consolidation test at $0 \%, 5 \%$ etc of added fine material respectively, Plaxis HS 0\%, $5 \%$ etc and Plaxis SS $0 \%, \mathbf{5 \%}$ etc means numerical modeling by Plaxis software using HS model and SS model at $\mathbf{0 \%} \mathbf{5 \%}$ etc of added fine material respectively.
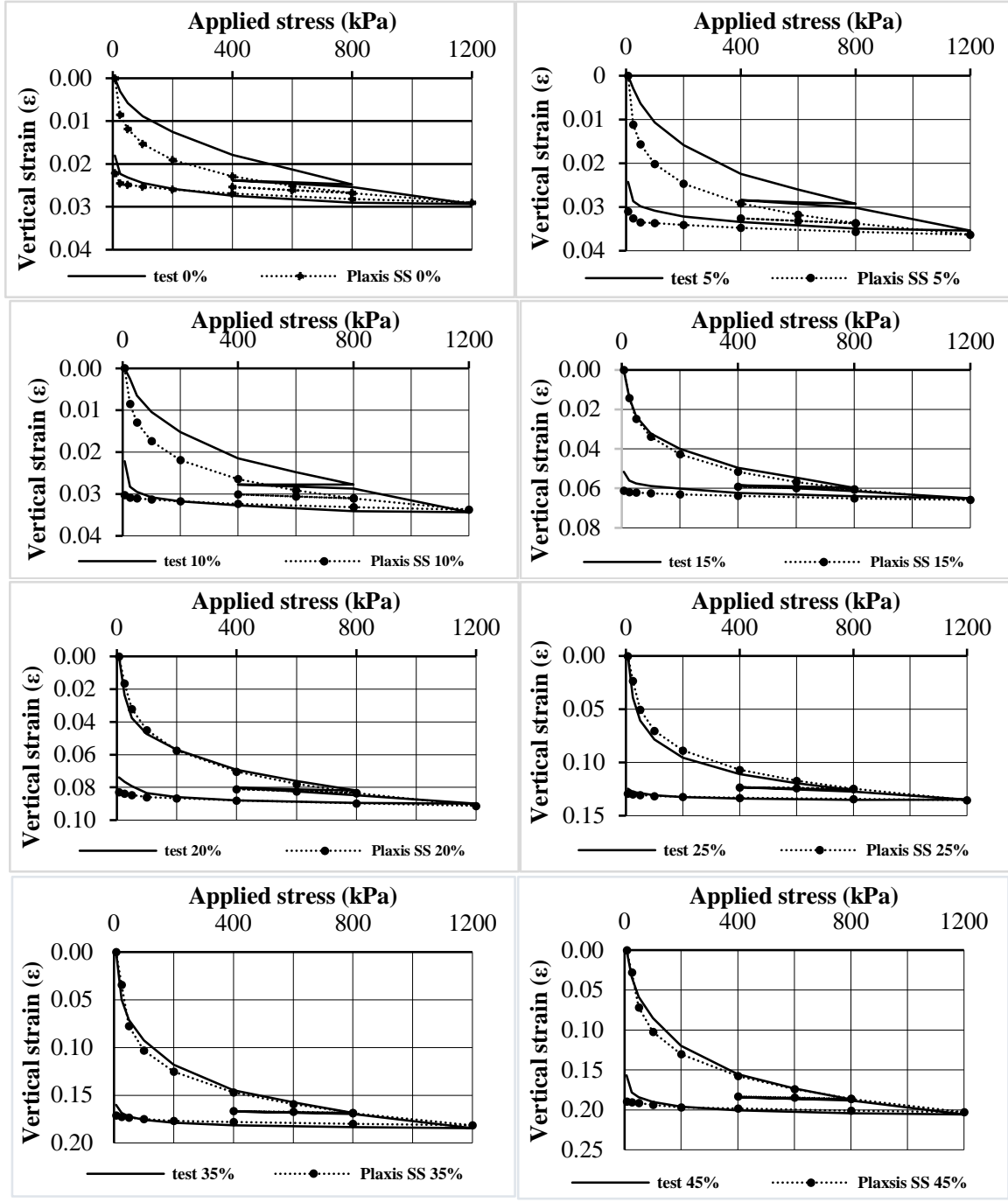

Figure 18. The curves of the stress-strain relationship for both laboratory onedimension consolidation test and numerical modeling using SS model 

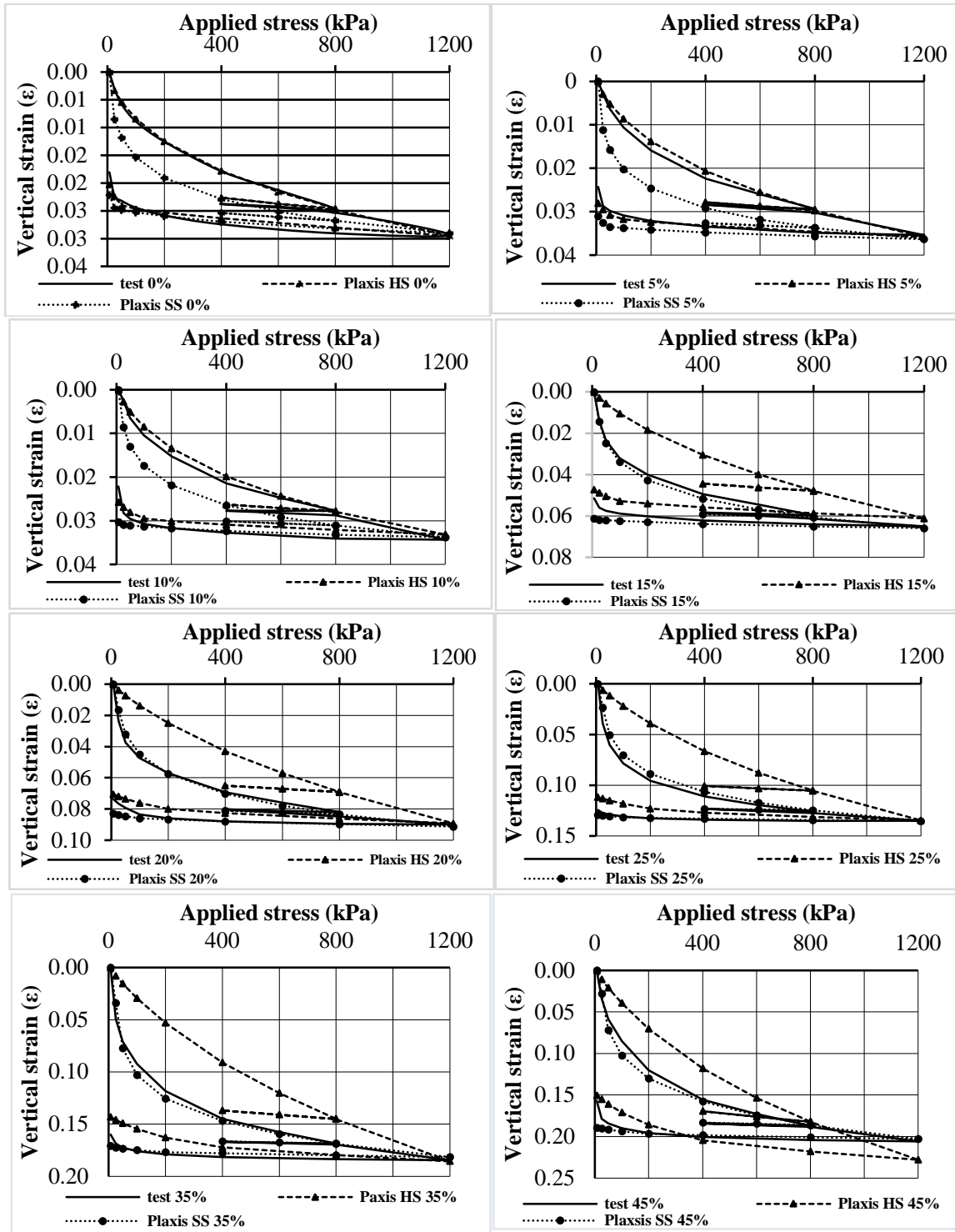

Figure 4. The curves of the stress-strain relationship for laboratory one-dimension consolidation test, numerical modeling using HS model, and numerical modeling using SS model 
Fig. 19 collects the three curves together (laboratory one-dimension consolidation test, numerical modeling using HS model, and numerical modeling using SS mode) to clarify the difference between them. It is noted that the HS model does not agree with the SS model and SS model curve is always more concave than HS model curve.

\section{Conclusions and recommendations}

\subsection{Conclusions}

Based on the results of the laboratory tests, it was found that fine materials mixed with soft poorly-graded sand for a certain percentage of fine material(silt) greater than $10-15 \%$ increase the compressibility of the sand mixture and it is proven by conducting numerous consolidation tests on prepared samples reconstituted in the laboratory. In order to study the consolidation behavior of sand when the percentage of fine materials increase, and through this research, the following conclusions and final recommendations are reached:

1. The compressibility of sandy soils depends on the percentage of fine materials that fill the voids between their sand grains. The percentage of fine materials that achieve the lowest compressibility is in the range of $10-15 \%$, which is affected by the level of applied stress.

2. The percentage of fine materials that achieve the lowest compressibility increases with increasing the applied stress.

3. The minimum values of $\mathrm{e}_{\max }$ and $\mathrm{e}_{\min }$ are related to the grain size distribution of the sand and the packing density. At transition zone, $\mathrm{e}_{\max }$ and $\mathrm{e}_{\min }$ have the minimum values due to the fact that the voids between the sand particles are completely filled with the fine materials. In zone 2, fine materials separate sand particles and make them move away from each other and void ratios start to increase again.

4. The transitional zone is affected by the grain distribution, size and shape of sand. For poorly graded sand, the transitional zone defined based on compressibility, is on a small range of fine material about (10-15\%), while the transitional zone is on a wider range of fine material for other types of sand and fine material according to previous studies.

5. The HS model is most appropriate when the percentage of soft materials added is up to $10 \%$ (zone 1), then the SS model becomes the most suitable when the percentage of fine materials exceeding 10\% (transition zone and zone 2).

\subsection{Recommendations}

1. Study the effect of relative density of the sandy soil, as in this research a relative density of $50 \%$ has been adopted considering sandy soil as medium dense. 
Therefore, it is preferable to use other relative densities to study their effect on the material model selected.

2. Repeating the tests on other types of soil mixtures by experimenting with adding different fine materials (other than silt) to the sand used, such as clay, as well as using other types of sand in the tests (other than soft poorly-graded sands) such as coarse poorly-graded sands or well-graded sand with a varied grain gradient, with the aim of establishing a useful data bank that is not limited to a specific type of mixtures only, and thus determining the transition zones of various sandy soils.

\section{Acknowledgement}

The author would like to express thanks to the faculty of civil engineering at Tishreen University, Latakia, Syria, and especially for the department and the laboratory of geotechnical engineering.

\section{References}

[1] P. V. Lade, Overview of Constitutive Models for Soils, Geo-Frontiers Congress, Austin, Texas, United States, 2005, pp. 1-34. doi: https://doi.org/10.1061/40771(169)1.

[2] D. M. Potts, L. Zdravkovic, T. I. Addenbrooke, K. G. Higgins, and N. Kovacevic, Finite element analysis in geotechnical engineering, Thomas Telford, London, 2001, 440 pages.

URL https://www.icevirtuallibrary.com/doi/pdf/10.1680/feaigea.27831.fm.

[3] T. I. Addenbrooke, D. M. Potts, and A. M. Puzrin, The influence of prefailure soil stiffness on the numerical analysis of tunnel construction, Geotechnique, 47 (3) (1997) pp. 693-712. doi: https://doi.org/10.1680/geot.1997.47.3.693.

[4] R. F. Obrzud, On the use of the Hardening Soil Small Strain model in geotechnical practice, Technical report Z_Soil.PC 100701, Zace Services Ltd, Lausanne, 2010, 17pages

URL http://www.geomod.ch/pdf/zsday-hard.pdf.

[5] S. Thevanayagam, Effect of Fines and Confining Stress on Undrained Shear Strength of Silty Sands, Journal of Geotechnical and Geoenvironmental Engineering, 124 (6) (1998) pp. 479-491. doi: https://doi.org/10.1061/(ASCE)1090-0241(1998)124:6(479). 
[6] S. Thevanayagam, T. Shenthan, and T. Kanagalingam, Role of intergranular contacts on mechanisms causing liquefaction and slope failures in silty sands, In Final report, USGS Award No. 01HQGR0032 and 99HQGR0021. U.S. Geological Survey, Department of the Interior, Reston, Va, 2003, 396 pages.

[7] E. L. D. Sibley and C. P. Polito, Insights on Threshold Fines Content, Geovirtual 2020 Resilience and Innovation Sep 14-16, 2020, 7 pages. URL https:// www.geovirtual2020.ca/wp-content/files/406.pdf.

[8] A. N. Alnmr, M. Omran Alzawi, and S. Abdallah, Study the Effect of the Percentage of Fines on the Compressibility Behavior of Sandy Soils, Tishreen University Journal for Research and Scientific Studies, 4 (2) (2017) pp. 2079-3001. (in Arabic)

URL http://www.journal.tishreen.edu.sy/index.php/engscnc/article/view/3677/0.

[9] K. Lupogo, Effect of fines mineralogy on the oedometric compressional behavior of sandy soils, Journal of Civil Engineering and Construction Technology, 4 (7) (2013) pp. 232-238. doi: https://doi.org/10.5897/JCECT12.025.

[10] D. Sarkar, M. Goudarzy, D. König, and T. Wichtmann, Influence of particle shape and size on the threshold fines content and the limit index void ratios of sands containing non-plastic fines, Soils and Foundations, 60 (3) (2020) pp. 621-633.

doi: https://doi.org/10.1016/J.SANDF.2020.02.006.

[11] H. Bahadori, A. Ghalandarzadeh, and I. Towhata, Effect of non plastic silt on the anisotropic behavior of sand, Soils and Foundation, 48 (4) (2008) pp. 531-545. doi: https://doi.org/10.3208/SANDF.48.531.

[12] T. D. Pitman, P. K. Robertson, and D. C. Sego, Influence of fines on the collapse of loose sands, Canadian Geotechnical Journal, 31 (5) (1994) pp. 728-739. doi: https://doi.org/10.1139/T94-084.

[13] D. D. Porcino, V. Diano, T. Triantafyllidis, and T. Wichtmann, Predicting undrained static response of sand with non-plastic fines in terms of equivalent granular state parameter, Acta Geotechnica 15 (4) (2019) pp. 867-882. doi: https://doi.org/10.1007/S11440-019-00770-5. 
[14] S. Likitlersuang, C. Chheng, and S. Keawsawasvong, Structural modelling in finite element analysis of deep excavation, Journal of GeoEngineering 14 (3) (2019) pp. 121-128.

doi: https://doi.org/10.6310/jog.201909_14(3).1.

[15] G. Song and E. X. Song, Selection of soil constitutive models for numerical simulation of foundation pit excavation, Gongcheng Lixue/Engineering Mechanics 31 (5) (2014) pp. 86-94. doi: https://doi.org/10.6052/j.issn.1000-4750.2012.08.0583.

[16] K. H. Law, K. H. Geotechnical, and S. Bhd, 3D finite element analysis of a deep excavation considering the effect of anisotropic wall stiffness Impact, 19th Southeast Asian Geotechnical Conference \& 2nd AGSSEA Conference (19SEAGC \& 2AGSSEA) , 2016, 6 pages.

URL https://www.researchgate.net/publication/327867642.

[17] W. Al-Ani, D. Wanatowski, and S. H. Chan, Numerical Analysis of Piled Embankments on Soft Soils, Geo-Shanghai, May 2014, pp. 30-39, doi: https://doi.org/10.1061/9780784413401.003.

[18] B. C. B. Hsiung, K. H. Yang, W. Aila, and L. Ge, Evaluation of the wall deflections of a deep excavation in Central Jakarta using three-dimensional modeling, Tunnelling and Underground Space Technology 72 (2018) pp. 8496.

doi: https://doi.org/10.1016/j.tust.2017.11.013.

[19] A. Hafudh and H. Aldefae, "Prediction of One-Dimensional Compression Test using Finite Elements Model,” International Journal of Engineering Research \& Technology (IJERT) 5 (05) (2016) pp. 359-363. URL http://www.ijert.org.

[20] M. Karstunen and A. Amavasai, Soft soil modelling and parameter determination, Chalmers University of Technology, Department of Architecture and Civil Engineering Gothenburg, Sweden, 2017, 78 pages. URL https://research.chalmers.se/publication/522789/file/522789_Fulltext.pdf.

[21] S. Likitlersuang, C. Surarak, D. Wanatowski, E. Oh, and A. Balasubramaniam, Finite element analysis of a deep excavation: A case study from the Bangkok MRT, Soils and Foundations 53 (5) (2013) pp. 756-773. doi: https://doi.org/10.1016/j.sandf.2013.08.013. 
[22] A. Truty and Z. Services, Hardening Soil model with small strain stiffness, Lausanne, Technical Report 080901, Zace Services Ltd, 2008, 42 pages. URL http://www.zsoil.com/zsoil_day/2008/Truty_HS-model.pdf.

[23] R. B. Brinkgreve, W. Broere, and D. Waterman, Plaxis 2D software manual version 8, Delft University of Technology and Plaxis Inc, Delft, The Netherlands, 2006.

URL http://www.plaxis.nl.

[24] ASTM International- Standard test method for particle-size analysis of soils,. ASTM D6913/D6913M-17, (2017)

doi: https://doi.org/10.1520/D6913_D6913M-17.

[25] ASTM International-Standard Test Method for Particle-Size Distribution (Gradation) of Fine-Grained Soils Using the Sedimentation (Hydrometer) Analysis, ASTM D7928-17 (2017).

doi: https://doi.org/ 10.1520/D7928-17.

[26] ASTM International- Standard Test Methods for Specifc Gravity of Soil Solids by Water Pycnometer, . D854-14 (2014).

doi: https://doi.org/10.1520/D0854-14.

[27] ASTM International- Standard Test Methods for Liquid Limit, Plastic Limit, and Plasticity Index of Soils, ASTM D4318-17e1 (2017).

doi: https://doi.org/10.1520/D4318 -17E01.

[28] ASTM International- Standard Practice for Classification of Soils for Engineering Purposes (Unified Soil Classification System), ASTM D248717e1 (2017). doi: https://doi.org/10.1520/D2487-17E01.

[29] ASTM International- Standard Test Methods for Minimum Index Density and Unit Weight of Soils and Calculation of Relative Density, ASTM D425400 (2000). doi: https://doi.org/10.1520/D4254-00.

[30] K. Lupogo, Effects of fines on mechanical behaviour of sandy soils, master thesis, 2009, 136 pages.

URL https://repository.tudelft.nl/islandora/object/uuid\%3Af4b5b6d0-8b00-44da-8011-cd664bfa96bd. 
[31] ASTM International- Standard Test Methods for One-Dimensional Consolidation Properties of Soils Using Incremental Loading, ASTM D2435 / D2435M - 11 (2020).

doi: https://doi.org/10.1520/D2435_D2435M-11R20.

[32] G. M. Mesri and B. V. Vardhanabhuti, Compression of granular materials, Canadian Geotechnical Journal 46 (4) (2009) pp. 369-392. doi: https://doi.org/10.1139/T08-123.

[33] M. Murat Monkul and G. Ozden, Compressional behavior of clayey sand and transition fines content, Engineering Geology 89 (3-4) (2006) pp. 195-205. doi: https://doi.org/10.1016/j.enggeo.2006.10.001.

[34] S. Thevanayagam and S. Mohan, Intergranular state variables and stressstrain behaviour of silty sands, Geotechnique 50 (1) (2015) pp. 1-23. doi: https://doi.org/10.1680/GEOT.2000.50.1.1. 